\title{
Comparative Analysis of Injury Severity Caused by Traffic Accidents Classified as Severe Injury in Police Database vs. MAIS 3+ Injury in Hospital Database -- First Pilot Research in Serbia
}

\author{
Sladjana Andjelic ${ }^{1, \star}$, Goran Colakovic ${ }^{1}$, Krsto Lipovac ${ }^{2}$, \\ Dalibor Pesic ${ }^{2}$, Zarko Plemic ${ }^{2}$, Emir Smailovic ${ }^{2}$
}

\author{
${ }^{1}$ Institute for Emergency Medical \\ Services, Belgrade, Serbia \\ ${ }^{2}$ Faculty of Transport and Traffic \\ Engineering, University of Belgrade, \\ Serbia \\ *Correspondence \\ novizivot94@gmail.com \\ (Sladjana Andjelic)
}

\begin{abstract}
Objective: Conduct a comparative analysis of injury severity (IS) caused by traffic accidents (TA) and classified as severe injury (SI) in police database vs. MAIS 3+ injury in hospital database, and determine correction factor (CF). Methods: Data were collected prospectively on the injured in TA examined by Emergency medical services. Were identified the numbers of fatalities, the numbers of patients transported to hospitals, and those examined at the scene of TA who refused further medical treatment and transport. IS was asssessed in hospital according to ICD, AIS and MAIS for each patient. The data on SBI were compared vs. MAIS 3+ and CF was determined. Results: 134 respondents were included: 55 drivers, 37 passengers, 23 pedestrians, 17 motorcyclists and 2 cyclists. $12 \%$ out of $17 \%$ of MAIS $3+$ patients were hospitalized. One patient with MAIS 5 died during the hospitalization. The comparative analyisis of IS as assessed in the police vs hospital database showed the ratio SI : MAIS $3+$ to be 1.2. Eighteen SIs belonged to MAIS 3+, one to MAIS 1 and one to MAIS 2. Four patients with MAIS 1 and 2 score sustained no injuries, according to the police report. Six moderate IS according to police data were classified as MAIS 3 in hospital registers. CF for MAIS 3+ was 0.316 and for minor IS was 0.016 . Conclusion: The results confirm that there are discrepancies in assessments of IS between police and hospital records and that it is neccessary to form a common database.
\end{abstract}

\section{Keywords}

Traffic accident, Severe injury, MAIS

\section{Introduction}

According to the World Health Organization, 1.35 million people worldwide are killed in traffic accidents (TA) annually ( 1 person every 25 seconds), 20 to 50 million are injured, and the costs are measured in billions of dollars [1] Traditionally, the main source of information on TA and injuries sustained in them are police reports done upon investigation at the scene. They contain crucial data to create statistical analyses at national levels in Europe (Community Road Accident Database - CARE) [2]. Police reports usually contain detailed information on the circumstances of the occurrence, the date and place of the TA, the category of participants, and the characteristics of the driver and the passengers in the vehicle, especially in TAs with serious injuries or fatalities. However, the persons who perform investigations are not medical professionals and cannot assess the injuries severity (IS) adequately. Therefore, police registers classify IS as either fatal, severe (SIS) or minor injury (MIS) [3].

In recent years, hospital records are another source of data [4]. They generally provide very little information on the circumstances of the TA, but contain demographic data on the person involved (age, sex and address) and on the 
TA B L E 1. Accessing injury severity for each patient according to the ICD 10, AIS and MAIS.

\begin{tabular}{|c|c|c|c|c|c|c|c|c|c|c|c|c|c|c|c|c|c|c|c|}
\hline No & ICD 10 & & & & & & & & & & & & AIS 1 & AIS 2 & AIS 3 & MAIS & AIS 4 & AIS 5 & AIS 6 \\
\hline 1 & S06.0 & R58 & V99 & S01 & T07 & S20.4 & S36 & S82.1 & S51.0 & $\mathrm{S} 32.1$ & Z01.6 & Z01.9 & 1202.5 & 8406.3 & 4106.2 & 5 & & & \\
\hline 2 & S13.4 & Z01.9 & & & & & & & & & & & 3106.1 & & & 1 & & & \\
\hline 3 & $\mathrm{~S} 13.4$ & $\mathrm{~S} 40.0$ & V43 & V72 & T90 & Z01.6 & & & & & & & 1206.1 & 3106.1 & 4104.1 & 1 & & & \\
\hline 4 & S13.4 & $\mathrm{S} 00$ & V49.4 & Z01.6 & & & & & & & & & 3106.1 & & & 1 & & & \\
\hline 5 & S13.4 & Z01.9 & & & & & & & & & & & 3106.1 & & & 1 & & & \\
\hline 6 & S13.4 & $\mathrm{S} 40.0$ & V72 & V43 & Т90 & Z01.6 & & & & & & & 3502.1 & 3106.1 & 1102.1 & 1 & & & \\
\hline 7 & $\mathrm{~S} 13.4$ & S00 & S33.5 & V49.4 & Z01.6 & & & & & & & & 6506.1 & 1106.1 & & 1 & & & \\
\hline 8 & S81.0 & Z01.9 & & & & & & & & & & & 8508.1 & & & 1 & & & \\
\hline 9 & S00.9 & V99 & Z01.9 & & & & & & & & & & 1106.1 & & & 1 & & & \\
\hline 10 & Т01.9 & & & & & & & & & & & & 9150.1 & & & 1 & & & \\
\hline 11 & S00.4 & $\mathrm{S} 00$ & $\mathrm{~S} 20.0$ & $\mathrm{~S} 20.2$ & $\mathrm{~S} 42$ & $\mathrm{~S} 42.1$ & $\mathrm{~S} 82.6$ & V49 & V99 & Т07 & Z01.6 & & 4104.2 & 7508.3 & 8508.2 & 3 & 1406.1 & 9150.1 & 3106.1 \\
\hline 12 & S30.4 & W19 & Z01.6 & Z01.9 & & & & & & & & & 8504.2 & & & 2 & & & \\
\hline 13 & S13.4 & S30.0 & S70.0 & S93.4 & V23 & V29.2 & Z01.6 & Z01.9 & & & & & 8504.2 & 8504.3 & 3106.1 & 3 & & & \\
\hline 14 & $\mathrm{~S} 00$ & $\mathrm{~S} 13.4$ & V49.4 & Z01.6 & Z01.9 & & & & & & & & 3106.1 & 1106.1 & & 1 & & & \\
\hline 15 & $\mathrm{~S} 13.4$ & V49.9 & Z01.9 & & & & & & & & & & 3106.1 & & & 1 & & & \\
\hline 16 & S00.0 & S60.2 & S61.0 & S 80.1 & V49.4 & Z01.6 & Z01.9 & & & & & & 1106.1 & 7508.2 & 8504.2 & 2 & & & \\
\hline 17 & $\mathrm{~S} 72.0$ & $\mathrm{R} 58$ & V99 & Z01.6 & Z01.9 & & & & & & & & 8508.3 & & & 3 & & & \\
\hline 18 & S003 & V49.4 & Z01.6 & Z01.9 & & & & & & & & & 2106.1 & & & 1 & & & \\
\hline 19 & S13.4 & V99 & Z01.6 & Z01.9 & & & & & & & & & 3106.1 & & & 1 & & & \\
\hline 20 & S90.3 & V09 & Z01.6 & Z01.9 & & & & & & & & & 8104.1 & & & 1 & & & \\
\hline 21 & $\mathrm{~S} 50.0$ & $\mathrm{R} 10.4$ & V09 & Z01.6 & Z01.9 & & & & & & & & 7504.1 & 5150.1 & & 1 & & & \\
\hline 22 & $\mathrm{~S} 13.4$ & $\mathrm{~S} 30.0$ & $\mathrm{~S} 80.0$ & V28.2 & Z01.6 & Z01.8 & Z01.9 & & & & & & 3106.1 & 8504.1 & & 1 & & & \\
\hline 23 & $\mathrm{~S} 13.4$ & Z01.6 & Z01.9 & & & & & & & & & & 3106.1 & & & 1 & & & \\
\hline 24 & S13.4 & V49.4 & Z01.6 & Z01.9 & Z47.0 & & & & & & & & 3106.1 & & & 1 & & & \\
\hline 25 & $\mathrm{~S} 50.0$ & S60.2 & & & & & & & & & & & 7504.1 & & & 1 & & & \\
\hline 26 & $\mathrm{~S} 80.0$ & S70.1 & & & & & & & & & & & 8504.1 & & & 1 & & & \\
\hline 27 & S01.0 & & & & & & & & & & & & 1150.2 & & & 2 & & & \\
\hline 28 & $\mathrm{~S} 13.4$ & V49.4 & Z01.6 & Z01.9 & & & & & & & & & 3106.1 & & & 1 & & & \\
\hline 29 & $\mathrm{~S} 42.1$ & Z01.9 & & & & & & & & & & & 7508.2 & & & 2 & & & \\
\hline 30 & S01 & & & & & & & & & & & & 1150.2 & & & 2 & & & \\
\hline 31 & S20.2 & S00 & S01.0 & S61.0 & V23 & V99 & Z01.6 & Z01.9 & & & & & 1150.2 & 1504.2 & 4504.3 & 3 & & & \\
\hline
\end{tabular}


TABLE 1. Continued.

\begin{tabular}{|c|c|c|c|c|c|c|c|c|c|c|c|c|c|c|c|c|c|}
\hline No & ICD 10 & & & & & & & & & & AIS 1 & AIS 2 & AIS 3 & MAIS & AIS 4 & AIS 5 & AIS 6 \\
\hline 32 & S10 & & & & & & & & & & 3106.1 & 7504.1 & & 1 & & & \\
\hline 33 & S00 & $\mathrm{S} 13.4$ & S50.0 & Z01.6 & Z01.9 & & & & & & 1106.1 & & & 1 & & & \\
\hline 34 & M65.1 & Z01.9 & & & & & & & & & 7204.1 & & & 1 & & & \\
\hline 35 & S13.4 & $\mathrm{S} 30.0$ & $\mathrm{~S} 80.0$ & V49.4 & Z01.6 & Z01.8 & Z01.9 & & & & 3106.1 & 8504.2 & 8504.1 & 2 & & & \\
\hline 36 & S01 & S01.0 & $\mathrm{S} 13.4$ & V43.0 & V49.4 & Z01.6 & Z01.9 & & & & 1106.1 & 1150.2 & 3106.1 & 2 & & & \\
\hline 37 & S70.1 & Z01.6 & $\mathrm{Z} 01.8$ & Z01.9 & & & & & & & 8504.1 & & & 1 & & & \\
\hline 38 & S13.4 & $\mathrm{S} 20$ & $\mathrm{~S} 30.0$ & V43 & V49.4 & Z01.6 & Z01.9 & & & & 3106.1 & 8504.2 & 4102.1 & 2 & & & \\
\hline 39 & S01.0 & $\mathrm{S} 02.2$ & $\mathrm{~S} 80.0$ & V18.2 & Z01.6 & Z01.8 & Z01.9 & & & & 1150.2 & 8504.1 & 2508.2 & 2 & & & \\
\hline 40 & S13.4. & Z01.6 & Z01.9 & & & & & & & & 3106.1 & & & 1 & & & \\
\hline 41 & S13.4 & V49.4 & Z01.6 & Z01.9 & & & & & & & 3106.1 & & & 1 & & & \\
\hline 42 & $\mathrm{~S} 00.0$ & S13.4 & $\mathrm{S} 20.2$ & S30.0 & S33.5 & $\mathrm{S} 50$ & S60.0 & $\mathrm{S} 80$ & $\mathrm{I} 20$ & Z01.6 Z01.9 & 1150.2 & 4404.3 & 6504.2 & 3 & & 8504.2 & 7504.1 \\
\hline 43 & $\mathrm{~S} 00$ & S01.0 & $\mathrm{S} 13.4$ & $\mathrm{~S} 23.5$ & $\mathrm{~S} 80.0$ & V49.4 & Z01.6 & Z01.9 & & & 1150.1 & 3106.1 & 4504.2 & 2 & 8504.1 & & \\
\hline 44 & S00 & V49.9 & S32.1 & Z01.6 & Z01.9 & & & & & & 1150.1 & & & 1 & & & \\
\hline 45 & $\mathrm{~S} 00$ & $\mathrm{~S} 82.3$ & V99 & Z01.6 & Z01.9 & & & & & & 1104.1 & 8508.2 & & 2 & & & \\
\hline 46 & S00 & S00.0 & S80.1 & & & & & & & & 1150.2 & 1104.1 & 8504.1 & 2 & & & \\
\hline 47 & S00 & S13.4 & V69.0 & V49.4 & Z01.6 & Z01.9 & & & & & 1104.1 & 3106.1 & & 1 & & & \\
\hline 48 & $\mathrm{~S} 13.4$ & V69.0 & Z01.6 & Z01.9 & & & & & & & 3106.1 & & & 1 & & & \\
\hline 49 & S00.5 & S00.9 & $\mathrm{S} 20.2$ & $\mathrm{~S} 22.4$ & V49.4 & V99 & I49.3 & J93 & Z01.6 & Z01.9 & 4508.3 & 4202.5 & 4104.1 & 5 & & 3106.1 & 2102.1 \\
\hline 50 & $\mathrm{~S} 00$ & S13.4 & $\mathrm{S} 23.3$ & V43 & Z01.6 & Z01.9 & & & & & 3106.1 & 4106.1 & 1104.1 & 1 & & & \\
\hline 51 & $\mathrm{~S} 13.4$ & Z01.9 & & & & & & & & & 3106.1 & & & 1 & & & \\
\hline 52 & S13.4 & S20.4 & V49.4 & Z01.6 & Z01.9 & & & & & & 4502.1 & 3106.1 & & 1 & & & \\
\hline 53 & $\mathrm{~S} 13.4$ & Z01.6 & Z01.9 & & & & & & & & 3106.1 & & & 1 & & & \\
\hline 54 & $\mathrm{~S} 20.2$ & S61 & $\mathrm{S} 80.0$ & S80.1 & V72 & Z01.6 & Z01.9 & & & & 4104.1 & 8504.1 & 7506.2 & 2 & 7504.1 & & \\
\hline 55 & $\mathrm{~S} 00$ & S13.4 & Z01.9 & & & & & & & & 1504.1 & 3106.1 & & 1 & & & \\
\hline 56 & $\mathrm{~S} 00$ & S13.4 & $\mathrm{S} 20.2$ & Z01.6 & Z01.8 & Z01.9 & & & & & 3106.1 & 4504.1 & & 1 & & & \\
\hline 57 & S13.4 & Z01.6 & Z01.9 & & & & & & & & 3106.1 & & & 1 & & & \\
\hline 58 & S13.4 & V43 & Z01.6 & Z01.9 & & & & & & & 3106.1 & & & 1 & & & \\
\hline 59 & S00 & $\mathrm{S} 42.0$ & $\mathrm{~S} 82.1$ & V03 & S82.1 & Z01.6 & Z01.9 & & & & 8408.3 & 4504.2 & 1104.1 & 3 & & & \\
\hline 60 & S13.4 & V49.9 & Z01.6 & Z01.8 & Z01.9 & & & & & & 3106.1 & & & 1 & & & \\
\hline 61 & $\mathrm{~S} 13.4$ & V49.9 & Z01.6 & Z01.8 & Z01.9 & & & & & & 3106.1 & & & 1 & & & \\
\hline 62 & $\mathrm{~S} 13.4$ & V49.9 & Z01.6 & Z01.9 & & & & & & & 3106.1 & & & 1 & & & \\
\hline
\end{tabular}


TABLE 1. Continued.

\begin{tabular}{|c|c|c|c|c|c|c|c|c|c|c|c|c|c|c|c|c|}
\hline No & ICD 10 & & & & & & & & & AIS 1 & AIS 2 & AIS 3 & MAIS & AIS 4 & AIS 5 & AIS 6 \\
\hline 63 & S70 & $\mathrm{S} 30$ & Z01.9 & & & & & & & 8502.1 & 5102.1 & & 1 & & & \\
\hline 64 & S70.1 & S81.0 & Z01.9 & & & & & & & 8504.1 & 8504.1 & & 1 & & & \\
\hline 65 & $\mathrm{~S} 30$ & Z01.9 & & & & & & & & 3106.1 & & & 1 & & & \\
\hline 66 & S00.0 & S13.4 & V43 & Z01.6 & Z01.8 & Z01.9 & & & & 1150.1 & 3106.1 & & 1 & & & \\
\hline 67 & S13.4 & Z01.6 & Z01.8 & Z01.9 & & & & & & 3106.1 & & & 1 & & & \\
\hline 68 & S00.8 & Z01.6 & Z01.9 & & & & & & & 1102.1 & & & 1 & & & \\
\hline 69 & S00.0 & Z01.6 & Z01.8 & Z01.9 & & & & & & 1150.1 & & & 1 & & & \\
\hline 70 & S13.4 & V43 & T90 & Z01.6 & Z01.8 & Z01.9 & & & & 1102.1 & 3106.1 & & 1 & & & \\
\hline 71 & S51.0 & S92.3 & V03 & Z01.6 & Z01.9 & & & & & 7508.1 & 7508.1 & & 1 & & & \\
\hline 72 & S13.4 & V49.4 & Z01.6 & Z01.9 & & & & & & 3106.1 & & & 1 & & & \\
\hline 73 & $\mathrm{~S} 13.4$ & V43 & Z01.6 & Z01.8 & Z01.9 & & & & & 3106.1 & & & 1 & & & \\
\hline 74 & S01.0 & S01.0 & Z01.6 & Z01.8 & Z01.9 & & & & & 1150.1 & 3106.1 & & 1 & & & \\
\hline 75 & S00.9 & S13.4 & Z01.9 & & & & & & & 1150.1 & 3106.1 & & 1 & & & \\
\hline 76 & $\mathrm{~S} 00$ & $\mathrm{~S} 13.4$ & V49.4 & Z01.6 & Z01.8 & Z01.9 & & & & 1104.1 & 3106.1 & & 1 & & & \\
\hline 77 & S00.0 & S10.9 & Z01.6 & Z01.8 & & & & & & 1102.1 & 3102.1 & & 1 & & & \\
\hline 78 & $\mathrm{~S} 00$ & S00.0 & S13.4 & $\mathrm{S} 30.0$ & Z01.6 & Z01.8 & Z01.9 & & & 1104.1 & 8504.1 & 3106.1 & 1 & & & \\
\hline 79 & S00 & S00.0 & $\mathrm{S} 42.2$ & $\mathrm{~S} 82.8$ & V43 & Z01.6 & Z01.9 & & & 1104.1 & 1150.1 & 7508.2 & 2 & 8504.1 & & \\
\hline 80 & S00.0 & S01.0 & S13.4 & V43 & Z01.6 & Z01.9 & & & & 1150.1 & 1102.1 & 3106.1 & 1 & & & \\
\hline 81 & S00.0 & S13.4 & V49.4 & & & & & & & 1150.1 & 3106.1 & 1104.1 & 1 & & & \\
\hline 82 & S00 & $\mathrm{S} 80.0$ & Z01.6 & Z01.9 & & & & & & 1104.1 & 8504.1 & & 1 & & & \\
\hline 83 & $\mathrm{~S} 13.4$ & $\mathrm{~S} 20.2$ & V03 & Z01.6 & Z01.9 & & & & & 4504.1 & 3106.1 & & 1 & & & \\
\hline 84 & $\mathrm{~S} 13.4$ & $\mathrm{~S} 20.2$ & S30.0 & Z01.6 & Z01.9 & & & & & 8504.1 & 4504.1 & 3106.1 & 1 & & & \\
\hline 85 & S00 & S06.3 & $\mathrm{S} 13.4$ & S81.0 & V23 & Z01.6 & Z01.9 & & & 1104.1 & 1604.3 & 8506.2 & 3 & 3106.1 & & \\
\hline 86 & S00 & $\mathrm{S} 22.1$ & $\mathrm{~S} 22.4$ & S27.1 & $\mathrm{S} 42$ & V99 & Z01.6 & Z01.9 & & 4508.2 & 6502.2 & 4206.4 & 4 & 4508.1 & & \\
\hline 87 & S02.0 & S02.6 & $\mathrm{S} 13.4$ & $\mathrm{~S} 20.2$ & S61 & $\mathrm{S} 80.0$ & $\mathrm{~S} 80.1$ & V72 & Y04 Z01.6 Z01.9 & 1406.4 & 2508.2 & 3106.1 & 4 & 4104.1 & 7102.1 & 8104.1 \\
\hline 88 & $\mathrm{~S} 42.1$ & $\mathrm{~S} 81.0$ & V23 & V49.9 & V99 & Z01.6 & Z01.9 & & & 4504.2 & 8508.1 & & 2 & & & \\
\hline 89 & S06.0 & $\mathrm{S} 30.0$ & Z01.6 & Z01.9 & W19 & & & & & 1610.3 & 8504.1 & & 3 & & & \\
\hline 90 & S70.1 & Z01.9 & & & & & & & & 8504.1 & & & 1 & & & \\
\hline 91 & S01.9 & S06.0 & $\mathrm{S} 41$ & V23 & V99 & Z01.6 & Z01.9 & & & 1102.1 & 4102.2 & 1610.3 & 3 & & & \\
\hline 92 & S01.0 & S91.1 & S92 & S92.3 & S92.4 & S92.5 & V03.0 & Z01.6 & Z01.9 & 8508.2 & 8508.2 & 8508.3 & 3 & 8508.1 & 1104.1 & 8508.1 \\
\hline 93 & $\mathrm{~S} 10$ & V23 & Z01.6 & Z01.9 & & & & & & 3102.1 & & & 1 & & & \\
\hline
\end{tabular}


TABLE 1. Continued.

\begin{tabular}{|c|c|c|c|c|c|c|c|c|c|c|c|c|c|c|c|}
\hline No & ICD 10 & & & & & & & & AIS 1 & AIS 2 & AIS 3 & MAIS & AIS 4 & AIS 5 & AIS 6 \\
\hline 94 & $\mathrm{~S} 30$ & V29.8 & V23 & Z01.6 & & & & & 5102.1 & & & 1 & & & \\
\hline 95 & S41 & $\mathrm{S} 42.0$ & V23 & S00 & V29.8 & Z01.6 & Z01.9 & & 1104.1 & 4108.2 & 4102.1 & 2 & & & \\
\hline 96 & S81 & Z04.9 & & & & & & & 8102.1 & & & 1 & & & \\
\hline 97 & S00.0 & S43 & & & & & & & 1102.1 & 7510.1 & & 1 & & & \\
\hline 98 & S00 & S00.0 & S40.0 & Z01.6 & Z01.9 & & & & 1102.1 & 1104.1 & 7504.1 & 1 & & & \\
\hline 99 & S00.0 & S13.4 & S40.0 & S52.5 & S62.0 & V03 & Z01.6 & Z01.9 & 7508.1 & 7508.2 & 3106.1 & 2 & 7504.1 & 1104.1 & \\
\hline 100 & $\mathrm{~S} 00$ & S50.0 & S60.2 & $\mathrm{S} 80.0$ & V03 & V09 & Z01.6 & Z01.9 & 8504.1 & 7504.1 & 1104.2 & 2 & 7504.1 & & \\
\hline 101 & $\mathrm{~S} 82.1$ & & & & & & & & 8508.1 & & & 1 & & & \\
\hline 102 & S50.9 & Z47.9 & & & & & & & 7502.1 & & & 1 & & & \\
\hline 103 & $\mathrm{~S} 80$ & S 80.0 & & & & & & & 8504.1 & 8102.1 & & 1 & & & \\
\hline 104 & S80.1 & & & & & & & & 8504.1 & & & 1 & & & \\
\hline 105 & S80.1 & & & & & & & & 8504.1 & & & 1 & & & \\
\hline 106 & $\mathrm{~S} 13.4$ & & & & & & & & 3106.1 & & & 1 & & & \\
\hline 107 & $\mathrm{~S} 72.0$ & Z47.9 & & & & & & & 8508.2 & & & 1 & & & \\
\hline 108 & $\mathrm{~S} 13.4$ & & & & & & & & 3106.1 & & & 1 & & & \\
\hline 109 & $\mathrm{~S} 13.4$ & & & & & & & & 3106.1 & & & 1 & & & \\
\hline 110 & $\mathrm{~S} 13.4$ & & & & & & & & 3106.1 & & & 1 & & & \\
\hline 111 & $\mathrm{~S} 72.3$ & & & & & & & & 8508.2 & & & 1 & & & \\
\hline 112 & $\mathrm{~S} 13.4$ & & & & & & & & 3106.1 & & & 1 & & & \\
\hline 113 & S33.5 & & & & & & & & 3106.1 & & & 1 & & & \\
\hline 114 & $\mathrm{~S} 13.4$ & & & & & & & & 3106.1 & & & 1 & & & \\
\hline 115 & S93.6 & & & & & & & & 8508.1 & & & 1 & & & \\
\hline 116 & S00.0 & & & & & & & & 1102.1 & & & 1 & & & \\
\hline 117 & S90.8 & & & & & & & & 8102.1 & & & 1 & & & \\
\hline 118 & $\mathrm{~S} 82.3$ & & & & & & & & 8508.2 & & & 2 & & & \\
\hline 119 & $\mathrm{~S} 12.2$ & S20.2 & S30.0 & $\mathrm{S} 40.0$ & S70.1 & & & & 6502.2 & 4104.1 & 8401.3 & 3 & 7104.1 & 8508.1 & \\
\hline 120 & S00.0 & & & & & & & & 1102.1 & & & 3 & & & \\
\hline 121 & $\mathrm{~S} 13.4$ & & & & & & & & 3106.1 & & & 1 & & & \\
\hline 122 & $\mathrm{~S} 16.0$ & M54.2 & & & & & & & 3102.1 & & & 1 & & & \\
\hline 132 & $\mathrm{~S} 20.2$ & & & & & & & & 4104.1 & & & 1 & & & \\
\hline 124 & S16.0 & M54.2 & & & & & & & 3102.1 & & & 1 & & & \\
\hline
\end{tabular}


TABLE 1. Continued.

\begin{tabular}{|c|c|c|c|c|c|c|c|c|c|c|c|c|}
\hline No & ICD 10 & & & & & AIS 1 & AIS 2 & AIS 3 & MAIS & AIS 4 & AIS 5 & AIS 6 \\
\hline 125 & S00.1 & $\mathrm{S} 20.2$ & & & & 2104.1 & 4104.2 & & 2 & & & \\
\hline 126 & S13.4 & S13.6 & S00.9 & & & 3106.1 & 3406.1 & 1102.1 & 1 & & & \\
\hline 127 & S00.9 & & & & & 1102.1 & & & 1 & & & \\
\hline 128 & $\mathrm{~S} 82.2$ & & & & & 8508.1 & & & 1 & & & \\
\hline 129 & S00.9 & $\mathrm{S} 40.8$ & S50 & & & 1102.1 & 7102.1 & 7502.1 & 1 & & & \\
\hline 130 & S13.4 & $\mathrm{S} 30.0$ & $\mathrm{~S} 40.0$ & & & 3106.1 & 8504.2 & 7102.1 & 2 & & & \\
\hline 131 & S13.4 & Z04.9 & & & & 3106.1 & & & 1 & & & \\
\hline 132 & S13.4 & & & & & 3106.1 & & & 1 & & & \\
\hline 133 & S01.3 & $\mathrm{S} 82.6$ & $\mathrm{~S} 82.8$ & $\mathrm{~S} 32.0$ & S32.5 & 8508.1 & 6506.2 & 8508.3 & 3 & 1102.1 & 8508.1 & \\
\hline 134 & S00.0 & S16 & & & & 1102.1 & 3102.1 & & 1 & & & \\
\hline
\end{tabular}

TA B L E 2. Injury severity (IS) in participants of traffic accidents according to HR.

\begin{tabular}{|c|c|c|c|c|c|c|c|}
\hline \multirow{2}{*}{\multicolumn{2}{|c|}{$\begin{array}{c}\text { IS } \\
\text { MAIS score }\end{array}$}} & \multicolumn{6}{|c|}{ Category of participants in TAs } \\
\hline & & drivers & pedestrians & passengers & motorcyclists & cyclists & Total \\
\hline & 1 & 17 & 9 & 12 & 6 & 1 & 45 \\
\hline & 2 & 32 & 3 & 24 & 5 & 1 & 65 \\
\hline \multirow[t]{3}{*}{ MAIS 3+ } & 3 & 6 & 10 & 1 & 5 & 0 & 22 \\
\hline & 4 & 0 & 0 & 0 & 1 & 0 & 1 \\
\hline & 5 & 0 & 1 & 0 & 0 & 0 & 1 \\
\hline Total & & 55 & 23 & 37 & 17 & 2 & 134 \\
\hline
\end{tabular}

TA B L E 3. Correction ratio of MAIS 3+ and SIS by category of participants.

\begin{tabular}{lcccccc} 
IS & drivers & pedestrians & passengers & motorcyclists & cyclists & total \\
MAIS 3+ & 6 & 11 & 1 & 6 & 0 & 24 \\
SIS & 5 & 9 & 1 & 4 & 1 & 20 \\
Correction ratio & 1.2 & 1.2 & No correction & 1.5 & - & 1.2 \\
\hline
\end{tabular}


hospitalization (dates of hospital admission and discharge, medical diagnosis with the code, mechanism or external cause of injury and medical interventions taken). To assess IS doctors use medical diagnoses, which are classified and encrypted by the International Statistical Classification of Diseases and Related Health Problems (ICD). Revisions 9 and 10 of ICD are currently in use [5], and injuries sustained in road traffic have separate codes in "the external causes" section, as well as codes for injury description.

A group of EU member states high representatives for traffic safety has realized that a universal definition of serious injury is necessary for the comparison and monitoring of IS. In January 2013, the definition of SIS in road traffic as non-lethal traffic injury was published with Maximum Abbreviated Injury Scale (MAIS) 3+ [6]. A year later, it was recommended that all EU countries collect SIS data according to this definition.

To determine MAIS 3+ variables must be selected from hospital data. MAIS 3+ represents the maximum value of Abbreviated Injury Scale (AIS) on a scale of 3 or more. The AIS - published by the Association for the Advancement of Automotive Medicine - is an internationally accepted tool used to describe the IS for each of nine regions of the body [7]. The AIS scale has two components: (1), a description of the injury (represents the unique numerical mark of each injury); and (2), grading of the IS in the range between 1 (minimal injury) and 6 (injury incompatible with life). The AIS scale grades IS as: minor - 1 ; moderate - 2; serious - 3; severe - 4; critical - 5; unsurvivable 6, unspecificied - 9. The AIS scale is estimated for each injury separately. AIS code can be determined directly or indirectly (derived from other encoding systems, e.g. ICD) [8]. Various tools are available to convert ICD codes to AIS codes, e.g. ICDmap90, ICDpic [9], ECIP and AAAM.

The study was conducted a comparative analysis of IS caused by traffic accidents (TA) in the inner-city area of Belgrade, classified as SI in the police registry (PR) vs. MAIS 3+ injuries as classified in hospital registry (HR), and determine the correction factor $(\mathrm{CF})$.

\section{Materials and Methods}

\subsection{Data collection}

Data were collected prospectively (from 14 to 31 August 2017) on the injured in TA in Belgrade examined by Emergency medical services (EMS). The numbers of patients transported to hospitals were identified, as well as the number of fatalities at the scene, and of those examined at the scene of the TA and who refused further medical treatment and transport. IS was asssessed in hospital according to ICD, AIS and MAIS for each patient. Finally, a comparison of data on IS obtained from the PR and those from the HR were compared.

The research included: a. creating a unique database designed for this research, $b$. estimation of IS by determining AIS and MAIS score, c. a comparative analysis of IS recorded by hospital doctors (HD) and the police, and $\mathrm{d}$. determination of $\mathrm{CF}$.

\subsection{Creating a unique database}

The data were entered into a previously created database with pre-defined variables for each person injured in a TA. The following variables were monitored at the pre-hospital level: name and surname, gender, age, personal ID number, date and time of receiving the call at emergency number 194 , locating the TA, wheter the police was already present at the scene when the EMS team arrived, the status of the participant in TA, the injured body regions, the hospital to which the patient was transported, the time when the patient was handed over to the hospital, and the diagnosis according to ICD-10 code. These data were collected from medical reports and electronic databases of EMS in Belgrade.

After the request was sent and the ethical approval to access the data from the HR was obtained, hospital data were collected in accordance with the Law on Personal Data Protection. Participants in TA brought in by EMS were identified in the HR by name, surname, unique personal identification number and location of TA. The following hospital variables were monitored: the date and time of the examination in the pre-admission clinic, the method of care (outpatient, observation, hospitalization), the outcome of the treatment (date and time of discharge or death), hospital diagnosis with codes according to ICD-10. Four out of six Belgrade hospitals that treat traumatized patients were included in the project. The remaining two did not participate in the research: one due to lengthy procedures for obtaining ethical approval, and the other one because there were no patients transported to that hospital during the monitoring period.

The frequency of the death of the injured at the scene of the accident (pre-hospital) was also observed, as well as the lethal outcome in the hospitalized patients within 30 days of hospital admission. The cause of death according to the severity of injuries by MAIS score was analysed for fatalities.

\subsection{Estimation of IS by determining AIS and MAIS score}

For each registered injury, respondents were diagnosed according to ICD 10 classification, which was then indirectly converted into the AIS scale by assessing the severity of individual injuries in different regions of the body (AIS 16), the 2008 revision. Finally, MAIS was determined by direct coding from AIS (AIS = MAIS). The subject of the observation were SI presented as AIS $3+$ in AIS coding system. That resulted in MAIS $3+$ as the equivalent of severe trauma.

\subsection{Matching the data obtained and forming a single unique database}

In the next study stage, data from hospital and police databases were matched. By this method, some missing 
TA B L E 4. Injury severity in participants in TA according to police records.

$\begin{array}{lcccccc}\text { IS } & \text { drivers } & \text { pedestrians } & \text { passengers } & \text { motorcyclists } & \text { cyclists } & \text { Total } \\ \text { SIS } & 5 & 9 & 1 & 4 & 1 & 20 \\ \text { MIS } & 49 & 14 & 34 & 12 & 1 & 110 \\ \text { NO INJURIES } & 1 & - & 2 & 1 & - & 4 \\ \text { TOTAL } & 55 & 23 & 37 & 17 & 2 & 134\end{array}$

TA B L E 5. Discrepancy between MAIS score and recorded severity of injury (severe - SIS and minor MIS).

\begin{tabular}{lcccc} 
HR & \multicolumn{4}{c}{ PR } \\
MAIS & SIS & MIS & No injuries & Total \\
1 & 1 & 41 & 3 & 45 \\
\hline 2 & 1 & 63 & 1 & 65 \\
3 & 16 & 6 & 0 & 22 \\
\hline 4 & 1 & 0 & 0 & 1 \\
5 & 1 & 0 & 0 & 1 \\
\hline Total & 20 & 110 & 4 & 134 \\
\hline
\end{tabular}

data were entered and the incorrectly recorded external causes (E-codes) were corrected in the hospital registry. The process of data matching in our study was based on one or more variables recored in both databases. The key variable is unique personal identification number, which enables identification on a 1-to-1 connection and a relatively easy and direct deterministic connection. However, this variable was often unavailable in one or both databases due to the Personal Data Protection Act. In those cases, a probabilistic method of identification was applied, i.e. a process of remote connection, based on several other variables: date and time of TA (and/or date and time of hospital admission), the location of TA, the gender and the date of birth (or age) of the injured person, the mode of transport.

Finally, a common database was formed.

\subsection{Determining correction factors}

Applying the CF to the police data is used to validate the number of MAIS 3+. CF are mathematical settings or adjustments prepared to assess the real number of SIS in order to correct the deviation from the correct values based on sampling or data selection method. In order for police data to become part of an integrated state/national database, correction of the magnitude of reporting on the number of SIS persons in TAs is necessary, which can not be achieved without access to some reference/comparative data, such as hospital data.

\section{RESULTS}

During the monitoring period, EMS teams intervened for 186 patients injured in TAs. The study did not include a total of 52 patients, including: one deadly injured person, 24 transported to a hospital where the ethical approval was not obtained, 24 patients who were examined at the scene refused transport to the hospital, and for 3 patients it was impossible to find data in HR.

The study included 134 patients, the average age of 47 years $(\mathrm{SD} \pm 4,2)$, predominantly male $(78-58,2 \%)$. 55 drivers, 37 passengers, 23 pedestrians, 17 motorcycle riders and 2 cyclists were injured as participants in TAs. In 95 TAs the police intervened before the arrival of the EMS team. Most TAs (96-71,6\%) occured between 08 and 20h.

The assessment of IS for each patient was initially done according to the ICD 10 classification of disease, then the AIS score was determined and finally MAIS was estimated (Table ??).

Table 2. presents the MAIS assessment by category of participants in TAs. $12 \%$ out of $17 \%$ of MAIS $3+$ patients were hospitalized. One patient with MAIS 5 died on the second day of hospitalization.

Comparative analysis of IS as assessed by HD (MAIS score) or the police (SIS) showed the ratio between SIS : MAIS 3+ injuries to be 1.2 (Table 3). More precisely, out of 24 MAIS $3+$ patients, the police classified 20 as SI. Of the total of 23 injured pedestrians, 11 had MAIS 3+ score, while according to the police 9 persons suffered SISs, which makes the SIS: MAIS 3+ ratio for pedestrians 1.2. Of the 55 injured drivers, 6 had MAIS $3+$, and according to PR 5 drivers had SIS. One passenger and one cyclist sustained SIS according to the police; however, HD assessed that the passenger had a MAIS 3+ injury, while the cyclist did not sustain a MAIS 3+ injury (Table 4).

Comparative analysis of SIS and MAIS shows that 18 SI belong to MAIS 3+ injuries, while one SIS belongs to MAIS 1 and 2. Six injuries classified by the police as MIS belong to MAIS 3 on the scale of injuries (Table 5).

According to police records, 20 persons sustained SIS, while 110 had MIS. It is important to point out that, according to $\mathrm{PR}, 4$ persons did not have any injuries, while HR show that those patients sustained injuries equivalent to those on MAIS 1 and 2 scale. The data confirm the differences in the SIS as assessed by HD and by the police. Even among TA participants with minor injuries (MAIS 1), in PR there is one person with SI. Table 6 shows in detail the differences in HD and PR by the severity of injuries (SIS vs. MAIS).

The largest number of unregistered bodily injuries in the PR referred to persons who suffered an injury equivalent to MAIS 1 and 2 scales (Table 7). There were no unidentified 
TA B L E 6. A comparison of police (PR) and hospital (HR) road injury data.

\begin{tabular}{lccccccc} 
HR & PR & pedestrians & drivers & passengers & motorcyclists & cyclists & total \\
\hline MAIS & SIS & 0 & 1 & 0 & 0 & 0 & 1 \\
\hline 1 & MIS & 9 & 15 & 11 & 5 & 1 & 41 \\
\hline & no injuries & 0 & 1 & 1 & 1 & 0 & 3 \\
& total & 9 & 17 & 12 & 6 & 1 & 45 \\
\hline MAIS & SIS & 0 & 0 & 0 & 0 & 1 & 1 \\
\hline 2 & MIS & 3 & 32 & 23 & 5 & 0 & 63 \\
\hline & no injuries & 0 & 0 & 1 & 0 & 0 & 1 \\
& total & 3 & 32 & 24 & 5 & 1 & 65 \\
\hline \multirow{2}{*}{ MAIS } & SIS & 8 & 4 & 1 & 3 & 0 & 16 \\
\hline 3 & MIS & 2 & 2 & 0 & 2 & 0 & 6 \\
\hline & total & 10 & 6 & 1 & 5 & 0 & 22 \\
\hline MAIS & SIS & 0 & 0 & 0 & 1 & 0 & 1 \\
\hline 4 & total & 0 & 0 & 0 & 1 & 0 & 1 \\
\hline MAIS & SIS & 1 & 0 & 0 & 0 & 0 & 1 \\
\hline 5 & total & 23 & 55 & 37 & 17 & 2 & 134 \\
\hline
\end{tabular}

TA B L E 7. Unaccounted patients (number and percentage) with severe (SIS) and minor (MIS) injury in PR compared to MAIS score.

\begin{tabular}{lccc} 
MAIS & SIS & MIS & Unaccounted (n - \%) \\
\hline 1 & 1 & 41 & $3-7$ \\
2 & 1 & 63 & $1-2$ \\
3 & 16 & 6 & $0-0$ \\
4 & 1 & 0 & $0-0$ \\
\hline 5 & 1 & 0 & $0-0$ \\
Unknown & 0 & 2 & $1-33$ \\
Total & 20 & 112 & $5-4$ \\
\hline
\end{tabular}

injuries in MAIS $3+$ group.

The methodology for calculating the total number of MAIS 3+ is based on PR. It takes into account the severity of injuries estimated by HD and the police, the injured not registered by the police (while registered by HD) and the total number of injured persons according to PR, on which basis the total number of the injured is calculated (Table 8).

The SIS and MAIS correction factor represents the ratio of the total number of MAIS 3+ injuries and the sum of SIS as recorded in both databases and the total number of SIS as recorded only by the police. The CF for SIS in our study was: $\mathrm{CFSI}=(16+1+1):(20+37)$; $\mathrm{CFSI}=0.316$. The $\mathrm{CF}$ for MIS compared to MAIS $3+$ injuries was: $=\mathrm{CF} 6:(110$ $+255) ; \mathrm{CF}=0.016$. The number of MAIS $3+$ is determined by multiplying the number of SISs recorded in PR with $\mathrm{Sf}$ 0.20 and the number of MIS with Sf 0.01 . In other words, on the basis of the conducted survey, the total number of MAIS 3+ injuries in Belgrade is obtained by multiplying the number of SIS recorded in police reports with Sf 0.316 and the number of MIS number with Sf $0.016(\mathrm{~N}=0.316$
$\mathrm{SI}+0.016 \mathrm{MSI})$.

\section{Limitations}

In the Republic of Serbia (RS) IS is established on the basis of a medical examination and a specialist doctor's opinion.

Both EMS and traffic police databases, which can be considered as the most complete records of injuries in TA participants, have certain shortcomings. Errors on the identity of the patient (name, surname, personal identification number) are not uncommon.

Police reports on TA often contain errors and the significance of those errors increases with further data processing. There are errors either in the recording of the type of TA or due to classification being too general, or the causes being unclear. Especially susceptible to errors are data related to IS due to different classification made by police and doctors.

When talking about EMS records, the first shortcoming is that, for justified reasons, a significant number of patients are treated as NNs (e.g. the injured person being unconscious, personal IDs being unavailable, etc.). For the injured persons without an established identity, electronic monitoring of health status is difficult as well as subsequently more comprehensive identification of IS through matching with data records kept in other health care institutions (HI). It should also be kept in mind that these are urgent cases in which the EMS team is focused on taking the necessary urgent procedures, so it is not able to "investigate" the data to be recorded.

Another shortcoming of pre-hospital records is the relatively short contact and monitoring of patients, and the objective inability to reliably determine IS, including MAIS $3+$ injuries.

Third, the EMS records do not contain data on the in- 
TA B LE 8. The values for calculating the correction factor for MAIS 3+ injuries.

\begin{tabular}{|c|c|c|c|c|c|c|c|}
\hline \multirow[b]{2}{*}{ MAIS } & \multicolumn{2}{|c|}{ Recorded in both databases } & \multirow[t]{2}{*}{ Not recorded in the PR } & \multicolumn{2}{|c|}{$\begin{array}{l}\text { Total number of the } \\
\text { injured according to PR }\end{array}$} & \multicolumn{2}{|c|}{$\begin{array}{c}\text { Estimated total number } \\
\text { of the injured }\end{array}$} \\
\hline & SI & MI & & SI & MI & SI & MI \\
\hline 1 and 2 & 2 & 104 & 4 & 37 & 255 & 39.1 & 363 \\
\hline 3 & 16 & 6 & 0 & 0 & 0 & 16 & 6 \\
\hline 4 & 1 & 0 & 0 & 0 & 0 & 1 & 0 \\
\hline 5 & 1 & 0 & 0 & 0 & 0 & 1 & 0 \\
\hline total & 20 & 110 & 4 & 37 & 255 & 57.1 & 369 \\
\hline
\end{tabular}

TA B L E 9. Comparative analysis of correction factors in $E U$ countries and Belgrade.

\begin{tabular}{lcc} 
& \multicolumn{2}{c}{ Correction factor } \\
& SBI & MBI \\
\hline France & 0.68 & 0.06 \\
Hungary & 0.48 & 0.04 \\
Greece & 0.46 & 0.12 \\
\hline The Netherlands & 0.39 & 0.006 \\
\hline Belgrade & 0.32 & 0.016 \\
\hline Spain & 0.26 & 0.02 \\
\hline The Czech Republic & 0.21 & 0.002 \\
\hline Scotland & 0.2 & 0.01 \\
\hline
\end{tabular}

jured in TAs that were transported to hospitals in vehicles other than ambulances, or those who were treated in public healthcare centers.

Fourth, although the injured in TAs on the territory of RS are mostly treated in state $\mathrm{HI}$, they can also be partially or completely treated in private $\mathrm{HI}$ in $\mathrm{RS}$ or in $\mathrm{HI}$ abroad.

\section{Discussion}

By adopting MAIS3+ as the definition of SIS in TAs, most European countries have conducted a joint analysis of PR and HR in road transport for the first time [10,11]. The pioneering steps in the implementation of the MAIS3 scale of injury were carried out by the Forum of European Road Safety Research Institutes (FERSI) in cooperation with the European Commission in the period 2014-2016 [12]. The current status of introducing MAIS $3+$ scale of injury shows that 17 European countries have the capability to assess SIS as MAIS 3+. In the remaining 14 countries, the process of introducing MAIS $3+$ is still at an early stage or has not started. Our study is a pioneering step for the introduction of MAIS 3+ in Serbia.

The European Commission has identified three main methods of MAIS $3+$ assessment [11]: 1 . applying the correction factor to police data; 2 . using only hospital data and 3. using matched / paired police and hospital data. We have chosen method number 3 .

The reliability and comparability of MAIS $3+$ is dependent on the method of data collection both in the method- ological sense and in the sense of presenting the acquired data sets from the related hospital. In some countries [2] IS is estimated directly using the AIS scale (France), others (Spain, the Netherlands) use software programs (eg. ICDmap90, ICDpic, ECIP and AAAM) to directly convert versions nine or ten of the ICD into AIS score, while the third group of countries (Great Britain, the Czech Republic) use indirect transformation of hospital data from other encoding systems, such as ICD, like we did in our study.

For the purposes of our study, the literature on direct encoding from AIS scores, or AIS scores by ICD conversion, was searched and analyzed using conversion tools that are applied in Europe. SCOPUS, ISI Web of Science and Pubmed databases were searched. Very limited literature was found.

De Bartolomeo et al. [13] and Greene et al. [14] compared injury severity levels determined by ICDpic with the levels of IS based on direct AIS coding. De Bartolomeo carried out a comparison of ICDPIC-ISS score (determined indirectly from Injury Score Severity - ISS) with d(direct)AIS-ISS score. On a small sample (289 cases), he concluded that despite the high potential, ICPICISS proved to be a weaker predictor of IS than direct AIS encoding. In Greene's study [14] on a sample of over 40,000 patients, ICDPIC-derived AIS score for each region of the body was compared with trauma registry AIS scores. It was concluded that the performance of ICDpic tools vary by region of the body; IS is well classified for thoracic and abdominal injuries, moderately for head and neck injuries, and it is most adequate for injuries to the face and extremities. ICDpic proved to be a reliable way of codifying injury according to degree.

We performed some additional analyses. In the German In-Depth Accident Study (GIDAS) database [15], during several years of monitoring, a direct MAIS coding for 16,695 injured persons in TAs from AIS 1998 and AIS 2008 was conducted. The application of AIS 1998 resulted in a $12 \%$ higher number of MAIS $3+$ than the application of AIS 2008 [16]. The reason for this is the more detailed specification of injuries in AIS 2008 and more adequate trauma care. Therefore, AIS 2008 which was also applied in our study is considered a gold standard for IS assessment [17]. Table 9. [18] presents the method for 1 of the AIS scores for each region of the body. Japan and the Czech Republic are two exceptions where IS is assigned 
exclusively by a doctor in hospital on the basis of available documentation (2). As recommended by Broughton et al. [19], IRTAD [20] and High Level Group on Road Safety [21], MAIS 3+ score was adopted to define IS in road traffic. In our study, the following categorization of MAIS injuries was made: MAIS 1 code 88 , MAIS 2 - 20, MAIS 3 - 12, MAIS 4 - 2 and MAIS 5 - 2 patients. Sixteen patients in total were hospitalized. It is important to point out that in the MAIS scale of injury it is not necessary to have a linear relationship with the likelihood of death [21]. Thus, in our study, one patient with MAIS 5 died but another one with the same MAIS score was hospitalized and discharged after 17 days. In Dutch connectivity studies, police data are linked to hospital records and compared to the ICD-derived MAIS scale [2]. The estimated real number of IS is now based on MAIS, and not on IS assessed by the police. Currently, only in Austria, Hungary, the Netherlands, Sweden and Slovakia, the medical database of injured persons in TAs is linked to the national database [2].

Calculating $\mathrm{CF}$ requires access to HR, which are considered more reliable than PR. Nowadays, HR are better for assessing the number of severely injured persons in TAs. Therefore, as in our study, hospital data are accessed in order to use $\mathrm{CF}$ to correct police data. The reference used in France for the development of CF represents matched police and hospital information in French Rhone county [22]. The results of our pilot study show that $\mathrm{CF}$ is 0.32 for SIS and 0.016 for MIS in Belgrade, which is lower than $\mathrm{CF}$ in France, Hungary, Greece and the Netherlands, but higher than CF in Spain, the Czech Republic and Sweden (Table 9) [2]. The values of CF in our study are the most similar to the values of coefficients in Spain.

The results obtained in this pilot study should be taken with reserve because they are based on a small number of injured persons in TAs and a short monitoring period (15 days). In order to obtain more reliable data, it is necessary to conduct research in a number of HIs throughout Serbia and for a longer period of time. The future perspective requires setting up an integrated database consisting of PR and HR.

Before future research, it is necessary to educate healthcare professionals on how to record MAIS 3+ injuries (by direct encoding using specialized software or indirectly through prior registration into the AIS scale) as well as on how to accurately enter data into the national database common for $\mathrm{HI}$ and police.

\section{ACKNOWLEDGMENTS}

The authors thank the Road Traffic Safety Agency of the Republic of Serbia for funding support for research on "System for recording data on injuries in traffic accidents in accordance with the recommendations of the European Commission".

Authors would like to thank doctors in the City Institute for emergency medical aid Belgrade and in four Belgrade hospital (Emergency center, Clinical-hospital centers Zvez- dara, Clinical-hospital centers Zemun, Institute of Orthopedic and Surgical Diseases "Banjica") for the data collection and analisys support.

The authors acknowledge the institutional support from Faculty of transport and traffic engineering University of Belgrade.

Thank numerous individuals participated in this study.

Thanks to all the peer reviewers and editors for their opinions and suggestions.

\section{CONFLICT OF INTEREST}

The authors have declared that no competing interests exist.

\section{FUNDING INFORMATION}

The work is part of the project entitled "System for recording data on injuries in traffic accidents in accordance with the recommendations of the European Commission". This project was supported by the Road Traffic Safety Agency of the Republic of Serbia (RTSA RS) (Grant No.: 221-40402-32/2017-07) (JN No. 26/17). RTSA RS agrees with the preparation and publication of this paper.

\section{REFERENCES}

[1] World Health Organization. Global status report on road safety 2018 . Geneva, 2018.

[2] Pérez K, Weijermars W, Amoros E, Bauer R, Bos N, Dupont E, et al. Practical guidelines for the registration and monitoring of serious traffic injuries, D7.1 of the H2020 project SafetyCube, 2016.

[3] Amoros E, Martin JL, Lafont S, Laumon B. Actual incidences of road casualties, and their injury severity, modelled from police and hospital data, France. Eur J Public Health. 2008;18:360-5.

[4] Pérez K, Seguí-gómez M, Arrufat V, Barberia E, Cabeza E, Cirera E, et al. Definición de alta hospitalaria, lesión grave y muerte por lesiones por tráfico. Gac Sanit. 2014;28:242-5.

[5] WHO Library Cataloguing-in-Publication Data. International statistical classification of diseases and related health problems. - 10th revision, Fifth edition. Geneva: World Health Organization; 2016.

[6] OECD/ITF. Road Safety Annual Report 2014, IRTAD, OECD Publishing, Paris, 2014.

[7] Jovanović D, Kaljević G. Sistemi skorovanja. NČ urgent med. 2015;21:16-22.

[8] ECIP: European Center for Injury Prevention, University of Navarra, Algorithm to transform ICD-10 codes AIS 90 (1998 update) and ISS, [version 1 for SPSS] [version 1.0 for STATA]. Pamplona, Spain 2006.with partial funding from the EU, DG SANCO Grant Agreement No 2004;119 Project Apollo WP2.

[9] Clark DE, Osler TM, Hahn DR. ICD Programs for Injury Categorization (ICDPIC), Version 3.0. 2010.

[10] Nuyttens N, Belleghem GV, Dupont E, Leblud J, Devos S, Putman $\mathrm{K}$, et al. The maximum abbreviated injury scale as a predictor of severe/fatal injuries in Belgian Road victims. Injury Prevention. 2016;22:S893.

[11] Weijermars W, Bos N, Schoeters A, Meunier JC, Nuyttens N, Dupont E, et al. Serious Road Traffic Injuries in Europe, Lessons from the EU Research Project SafetyCube. Transportation Research Record Journal. 2018;00:1-9.

[12] Auerbach K, and Schmucker U. Country Survey State of the Art of MAIS 3+ Assessment in the FERSI Member States and EU/EEA countries. FERSI working group "Injury Classification”, 2016.

[13] Di Bartolomeo S, Tillati S, Valent F, Zanier L, Barbone F. ISS mapped 
from ICD-9-CM by a novel freeware versus traditional coding: a comparative study. Scand J Trauma Resusc Emerg Med 2010;18:17.

[14] Greene NH, Kernic MA, Vavilala MS, Rivara FP. Validation of ICDPIC software injury severity scores using a large regional trauma registry. Injury Prevention. 2015;21:325-30.

[15] Otte D, Haasper C, Jaensch M. Injury protection and accident causation parameters for vulnerable road users based on German InDepth Accident Study GIDAS. Accident; analysis and prevention. 2012;44:149-53.

[16] Niesen S, Auerbach K, Lerner M, Pastor C, Schepers A, Wisch M, et al. Estimation of the number of seriously injured road traffic casualties in Germany based on GIDAS, using a decision tree method and the TraumaRegister DGU. IRCOBI Conference. 2016,IRC-16-19.

[17] European Center for Injury Prevention, University of Navarra. Algoritm to transform ICD-10 codes into AIS 90.2006.

[18] Abbreviated Injury Scale. Available: https://en.wikipedia. org/wiki/Abbreviated_Injury_Scale

[19] Broughton J, Keigan M, Yannis G, Evgenikos P, Chaziris A, Papadimitriou E, et al. Estimation of the real number of road casualties in Europe. Saf. Sci. 2010;48:365-71.

[20] IRTAD. Reporting on Serious Road Traffic Casualties: Combining and using different data sources to improve understanding of non-fatal road traffic crashes, International Traffic Safety Data and Analysis Group, OECD/ITF, Paris, 2011.

[21] Breen J, Working document for the meeting of the High Level Group on Road Safety 27th June 2012, Copenhagen.

[22] Amoros E, Martin JL, Lafont S, Laumon B. Actual incidences of road casualties, and their injury severity, modelled from police and hospital data, France. Eur J Public Health. 2008;18:360-65.

How to cite this article: Sladjana Andjelic, Goran Colakovic, Krsto Lipovac, et al. Comparative Analysis of Injury Severity Caused by Traffic Accidents Classified as Severe Injury in Police Database vs. MAIS 3+ Injury in Hospital Database First Pilot Research in Serbia. Signa Vitae. 2020;16(1):13-24. doi:10.22514/sv.2020.16.0003. 